REVIEW

\title{
Membrane associated proteases and their inhibitors in tumour angiogenesis
}

\author{
A Noel, C Maillard, N Rocks, M Jost, V Chabottaux, N E Sounni, E Maquoi, D Cataldo, J M Foidart
}

J Clin Pathol 2004;57:577-584. doi: 10.1136/icp.2003.014472

Cell surface proteolysis is an important mechanism for generating biologically active proteins that mediate a range of cellular functions and contribute to biological processes such as angiogenesis. Although most studies have focused on the plasminogen system and matrix metalloproteinases (MMPs), recently there has been an increase in the identification of membrane associated proteases, including serine proteases, ADAMs, and membrane-type MMPs (MT-MMPs). Normally, protease activity is tightly controlled by tissue inhibitors of MMPs (TIMPs) and plasminogen activator inhibitors (PAls). The balance between active proteases and inhibitors is thought to determine the occurrence of proteolysis in vivo. High concentrations of proteolytic system components correlate with poor prognosis in many cancers. Paradoxically, high (not low) PAI-1 or TIMP concentrations predict poor survival in patients with various cancers. Recent observations indicate a much more complex role for protease inhibitors in tumour progression and angiogenesis than initially expected. As knowledge in the field of protease biology has improved, the unforeseen complexities of cell associated enzymes and their interaction with physiological inhibitors have emerged, often revealing unexpected mechanisms of action.

See end of article for authors' affiliations

Correspondence to: Dr A Noel, Laboratory of Biology of Tumour and Development, University of Liège, 4000 Sart-Tilman, Liège, Belgium; agnes. noel@ulg.ac.be

Accepted for publication 1 January 2004
A ngiogenesis, the formation of new blood vessels from pre-existing ones, is essential for sustained tumour growth beyond a critical size of 1-2 mm. Moreover, increased angiogenesis promotes tumour cell penetration into the circulation and thereby metastatic dissemination. Tumour vessels can develop through different mechanisms, including sprouting or intussusception from pre-existing vessels, the mobilisation of circulating endothelial precursors from the bone marrow, and the recruitment of lymphatic vessels (lymphangiogenesis). ${ }^{1}$ Different proteolytic enzymes, including serine proteases (SPs) and matrix metalloproteinases (MMPs), have been implicated in angiogenesis. ${ }^{2}$ The human genome sequence has revealed more than 500 genes encoding proteases or proteaselike products, ${ }^{3}$ so that many exciting discoveries about the functions of proteases in physiological and neoplastic processes can be expected in the near future.

\begin{abstract}
"Recent information has underlined the importance of cell surface proteases, their receptors/activators, and their inhibitors during angiogenesis"
\end{abstract}

Initially, the basic idea for the involvement of SPs and MMPs during cancer progression was that the degradation of extracellular matrix components should contribute to different events, such as provisional matrix remodelling, basement membrane breakdown, and cell migration and invasion. In addition to degrading extracellular matrix components, proteinases have also been implicated in the activation of cytokines, and in the release of growth factors sequestered within the extracellular matrix..$^{4-6}$ Recent information has underlined the importance of cell surface proteases, their receptors/ activators, and their inhibitors during angiogenesis. New membrane associated proteases have been identified and include: type I and type II transmembrane SPs, membrane-type MMPs (MT-MMPs), and ADAMs (a disintegrin and metalloproteinase). In this review, we will use selected examples to illustrate the influence of cell surface proteolysis and the resulting alteration of the pericellular microenvironment on the tumoral angiogenic process. This review will also delineate the unexpected role of physiological inhibitors of membrane associated proteases such as plasminogen activator type 1 (PAI-1) and tissue inhibitors of MMP-2 (TIMP-2).

\section{PROTEOLYTIC SYSTEMS INVOLVED IN CELL SURFACE PROTEOLYSIS}

Pericellular proteolysis was initially associated with the classic plasminogen-plasmin system and then extended to at least three new classes of proteases: MT-MMPs, ADAMs, and membrane anchored SPs (figs 1 and 2). These cell surface proteases are integral membrane proteins of the plasma membrane or are anchored to the membrane through a glycosyl phosphatidylinositol (GPI) linkage.

\footnotetext{
Abbreviations: $A D A M s$, a disintegrin and metalloproteinase; bFGF, basic fibroblast growth factor; GPI, glycosyl phosphatidylinositol; MMP, matrix metalloproteinase; MT, membrane-type; PAI, plasminogen activator inhibitor; $S P$, serine protease; TIMP, tissue inhibitor of matrix metalloproteinases; TTSP, type II transmembrane domain serine protease; UPA, urokinase plasminogen activator; UPAR, urokinase plasminogen activator receptor; VEGF, vascular endothelial growth factor
} 


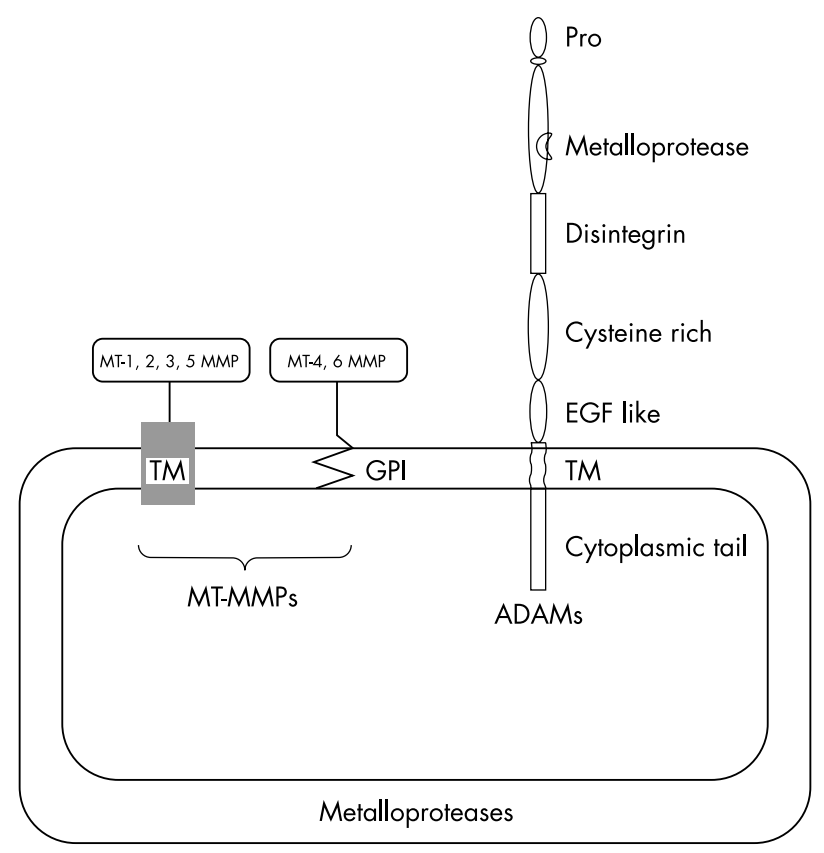

Figure 1 Membrane-type metalloproteases (MT-MMPs) are associated with the plasma membrane through a transmembrane domain (TM) or a glycosyl phosphatidylinositol (GPI) link. ADAMs (a disintegrin and metalloprotease) contain a transmembrane domain. EGF, epidermal growth factor; Pro, prodomain.

\section{Plasminogen-plasmin system}

The plasminogen-plasmin system ${ }^{7-12}$ plays a major role in physiological and pathological processes. It is composed of an inactive proenzyme, plasminogen, which can be converted to plasmin by two SPs: urokinase plasminogen activator (uPA) and tissue-type plasminogen activator. This system is controlled at the level of the plasminogen activators by plasminogen activator inhibitors (PAI-1 and PAI-2), and at the level of plasmin by 2 antiplasmin. uPA binds to a cell surface GPI anchored receptor (UPAR) and controls pericellular proteolysis (fig 2). ${ }^{13}{ }^{14}$ Plasmin displays a broad spectrum of activity and can degrade several glycoproteins (laminin, fibronectin), proteoglycans, and fibrin to activate pro-MMPs and to activate or release growth factors from the extracellular matrix (latent transforming growth factor $\beta$, basic fibroblast growth factor (bFGF), and vascular endothelial growth factor (VEGF) ${ }^{4}$ (fig 3$)$ ). Studies of knockout mice have revealed that one fundamental role of plasminogen/ plasmin in vivo is fibrinolysis. ${ }^{13}$ Pathological manifestations of plasminogen deficiency, such as impaired wound healing, can be rescued if fibrinogen deficiency is genetically superimposed ${ }^{15}$ However, given the broad spectrum of activity of plasmin described above, it is conceivable that in addition to fibrin, multiple targets of plasmin are biologically relevant in vivo during physiological and pathological processes. Together with uPAR and PAI-1, uPA is involved in mitogenic, chemotactic, adhesive, and migratory cellular activities. ${ }^{14}{ }^{16-21}$ The uPA-uPAR complex interacts with vitronectin, a multifunctional matrix glycoprotein and with $\beta 1$ and $\beta 3$ integrins, thereby participating in cell anchoring and migration. ${ }^{16} 2223$ In addition, despite the lack of a transmembrane domain, uPAR colocalises with caveolin, which can bind signalling molecules and stimulate signal transduction through the UPAR. $^{19} 2224$

"Plasmin displays a broad spectrum of activity and can degrade several glycoproteins, proteoglycans, and fibrin to activate pro-matrix metalloproteases and to activate or release growth factors from the extracellular matrix"

\section{MT-MMPs}

MMPs comprise a broad family of 24 zinc binding endopeptidases that degrade extracellular matrix components and

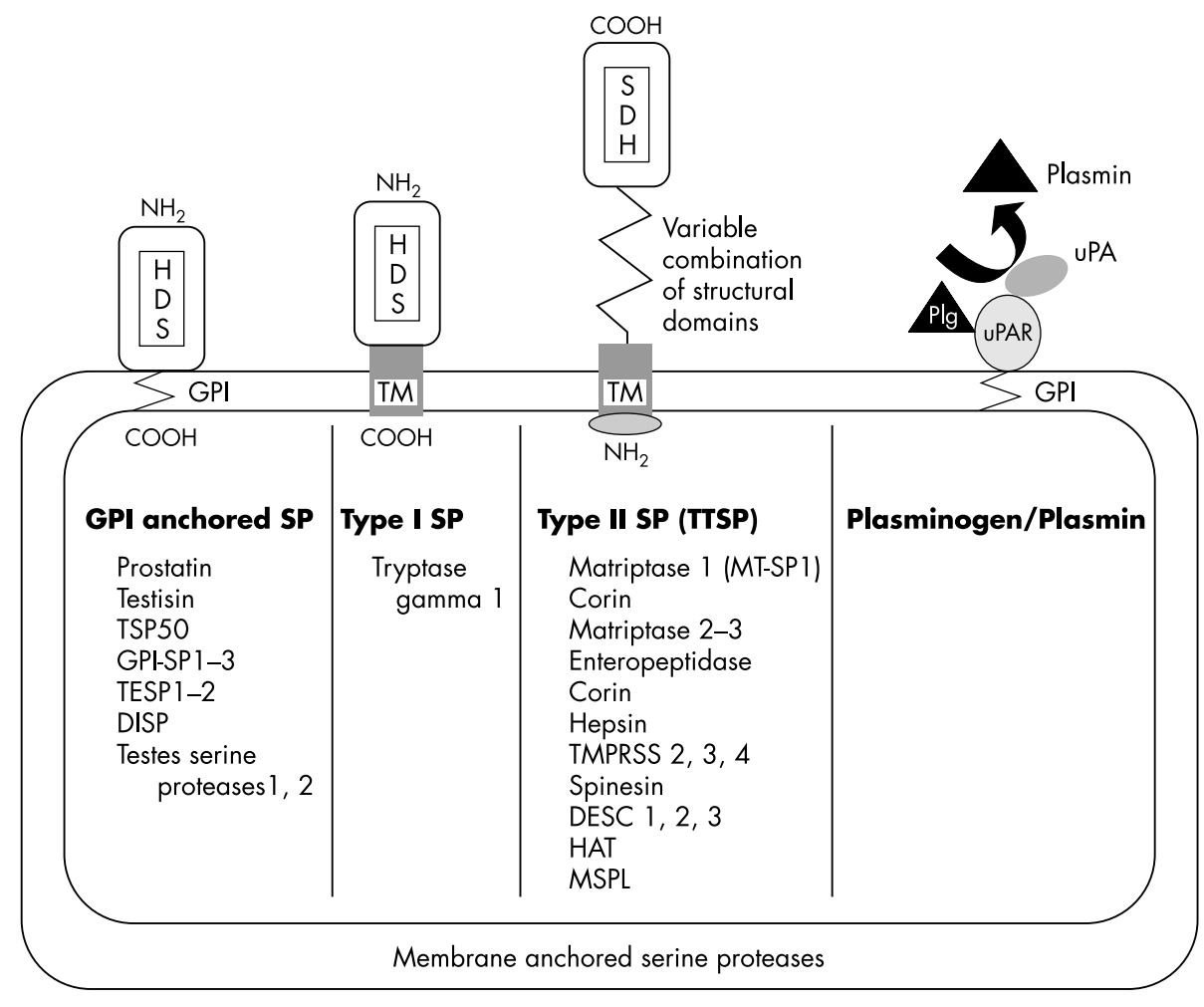

Figure 2 Membrane anchored serine proteases (SPs) are linked to the plasma membrane through a glycosyl phosphatidylinositol anchor (GPI anchored SP), a type I transmembrane domain (TM; type I SP), or a type II TM (type II SP or TTSP). The urokinase plasminogen activator (UPA) receptor (UPAR) containing a GPI link participates in the activation of UPA, leading to the conversion of plasminogen $(\mathrm{Plg})$ into plasmin at the cell surface. 
- ECM remodelling

- Activation of proteases

- Processing of growth factors

- Shedding of cell surface molecules

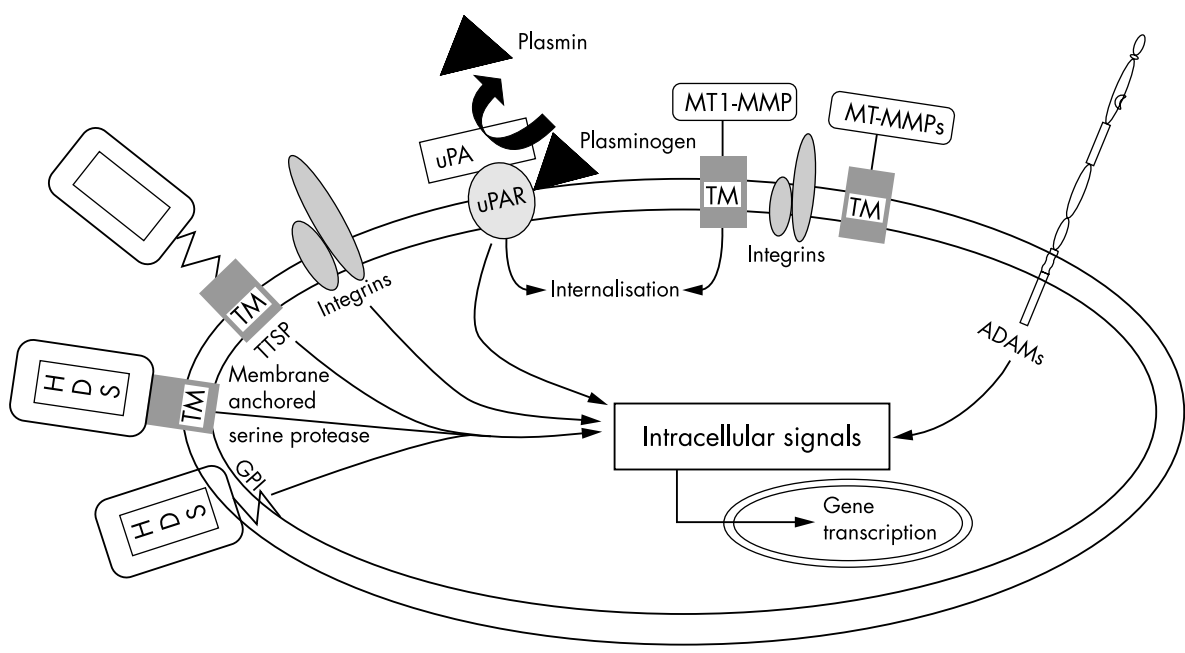

Figure 3 Metalloproteases (MTMMPs, ADAMs), membrane anchored serine proteases (SPs), and the plasminogen/plasmin system are adequately positioned at the plasma membrane to participate in a cascade of protease activation, to activate receptors, growth factors, and cytokine/chemokines, to shed cell surface molecules, and to participate in extracellular matrix (ECM) remodelling. The presence of a cytoplasmic domain may endow these proteins with the capacity to interact with the cytoskeleton and/or with intracellular signalling molecules, thereby influencing cell shape, differentiation, migration, and gene transcription. ADAMs, a disintegrin and metalloproteinase; GPI, glycosyl phosphatidylinositol; MT-MMP, membrane-type matrix metalloproteinase; TM, transmembrane domain; TTSP, type II transmembrane domain serine protease; UPA, urokinase plasminogen activator; UPAR, urokinase plasminogen activator receptor. process bioactive mediators. This family has been recently described in excellent reviews. ${ }^{25-28}$ MMP activity is tightly controlled by endogenous inhibitors, such as $\beta 2$ macroglobulin, and specific MMP inhibitors, the TIMPs. TIMP1, TIMP2, TIMP3, and TIMP4 reversibly inhibit MMPs in a $1: 1$ stoichiometric fashion..$^{25}$ The different TIMPs differ in tissue specific expression, their ability to inhibit various MMPs, and their capacity to interact with pro-MMPs. ${ }^{25}$ In addition, RECK (reversion induction cystein rich protein with kazal motif) is the only known membrane bound MMP inhibitor. ${ }^{30}$ It has been reported to contribute to tumour development and angiogenesis. ${ }^{31}$

Although most MMPs are secreted as soluble enzymes into the extracellular milieu, most of the newly identified MMPs are MT-MMPs, which activate latent MMPs (MMP-2) and degrade some extracellular matrix proteins. These MT-MMPs are associated with the cell surface by at least three distinct mechanisms, namely ${ }^{28}$ : (a) a type I transmembrane domain for MT1, MT2, MT3, and MT5 MMPs ${ }^{32-34}$; (b) a GPI linkage for MT4 and MT6 MMPs (fig 1); and (c) a type II transmembrane domain for MMP23/cystein array MMP. MT1-MMP (MMP-14) is the prototypic member of the MTMMPs and its expression has been associated with various pathophysiological conditions. ${ }^{35}$ It is thought to be the main activator of pro-MMP-2, through the formation of a complex involving MMP-2, its inhibitor TIMP2, MTl-MMP, and $\alpha_{\mathrm{V}} \beta_{3}$ integrin (fig 3). ${ }^{36-39}$ Although MT2-MMP activates MMP-2 in a TIMP2 independent pathway, ${ }^{40}$ the TIMP2 requirement for this activation process by MT3-6-MMPs remains to be established. In addition to this activator function, MTlMMP activates pro-MMP- $13^{41}$ and displays a broad spectrum of activity against various matrix components. ${ }^{42-47}$ However, it has substrates that extend beyond extracellular matrix components, such as cell surface molecules including CD $44,{ }^{48}$ pro $\alpha_{V}$ integrin, ${ }^{39}$ and transglutaminase. ${ }^{49}$ Like other MMPs, the activity of MT-MMP is regulated at three main levels: transcription, proenzyme activation, and inhibition. ${ }^{528}$ The shedding of MT-MMP appears to be an additional way to control enzyme localisation and activity. ${ }^{50}$ In addition, endocytosis emerges as a main mechanism regulating at least MT1-MMP activity. ${ }^{51-53}$

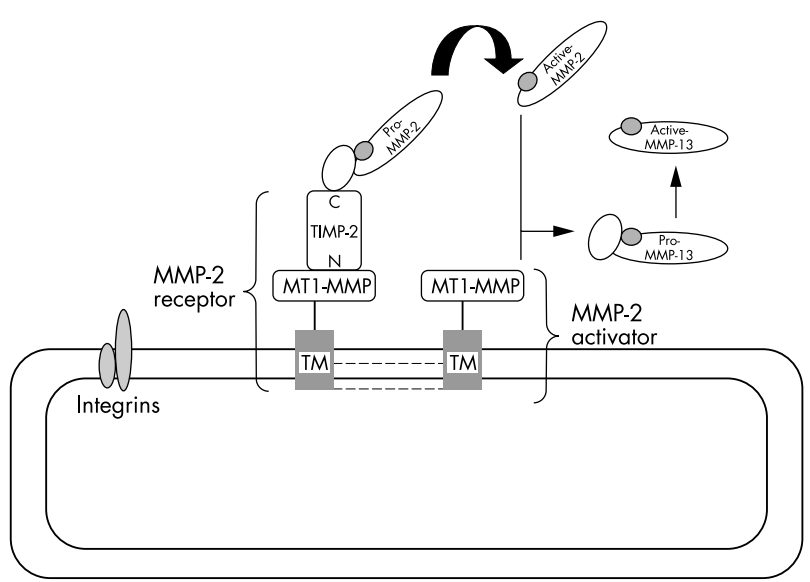

Figure 4 Activation of pro-MMP-2 and pro-MMP-13 by MT1-MMP. A model for the activation of pro-MMP-2 has been proposed in which the catalytic domain of MT1-MMP binds to the N-terminal portion of TIMP-2 $(\mathrm{N})$, leaving the TIMP-2 C-terminal region (C) available for binding to the haemopexin-like domain of pro-MMP-2. ${ }^{36}{ }^{54}$ This ternary complex (MMP-2 receptor) is believed to localise pro-MMP-2 close to a TIMP-2 free MT1-MMP molecule (MMP-2 activator) able to initiate the activation of pro-MMP-2. This may be favoured by MT1-MMP oligomerisation through the extracellular domain and the intracytoplasmic tail (dotted lines). MT2-MMP does not require TIMP-2 to activate MMP-2 and it is not known whether the other MT-MMPs form a complex with TIMP-2. Integrins such as $\alpha_{\gamma} \beta_{3}$ might also form part of this activation cascade by interacting with MT1-MMP. A third focus of activation probably involves TSSP, because MT-SPI has been reported to activate UPA. MMP, matrix metalloproteinase; MT, membrane-type; SP, serine protease; TIMP, tissue inhibitor of matrix metalloproteinases; TTSP, type II transmembrane domain serine protease; uPA, urokinase plasminogen activator.

\section{A disintegrin and metalloproteinases (ADAMs)}

ADAMs comprise a family of at least 24 multifunctional membrane proteins. ${ }^{55-58}$ Structurally related to snake venom metalloproteinases, they display a complex domain organisation consisting of: (a) a prodomain using a cystein switch mechanism similar to that of MMPs; (b) a metalloproteinase domain endowing (or not endowing) the enzyme with 
proteolytic activity; (c) a disintegrin-like domain mediating cell-cell interaction via integrins; (d) a cystein rich region that may be involved in cell fusion; (e) an epidermal growth factor-like domain; (f) a transmembrane region; and (g) a cytoplasmic tail (fig 1). In some ADAMs, particularly those with protease activity, the cytoplasmic tail contains a potential phosphorylation site, suggesting potential signalling activity. ${ }^{59}$ Originally associated with reproductive processes, such as spermatogenesis and sperm-egg fusion, more recently they have been linked to other biological processes, such as cell migration and adhesion, and activation of signalling pathways by shedding of membrane bound cytokines and growth factors (fig 4). ${ }^{5960}$ The first well described ADAM, TACE (tumour necrosis factor $\alpha$ converting enzyme; ADAM17) is essential for the proteolytic release or activation of growth factors and cytokines, including all epithelial growth factor ligands and tumour necrosis factor $\alpha$, in addition to the shedding of ligands for cell surface receptors. ${ }^{61}$ Therefore, these multifunctional molecules are thought to play key roles in different steps of cancer progression. Accordingly, some ADAMs are overexpressed in cancers, ${ }^{62-64}$ and their activity can be blocked by TIMPs or synthetic MMP inhibitors. ${ }^{65}$ ADAM15 contains a unique RGD sequence in its disintegrin domain, which specifically mediates adhesion to $\alpha_{\mathrm{V}} \beta_{3}$ integrin. ${ }^{66}$ It is therefore conceivable that some ADAMs, through their interaction with key integrins or their proteolytic activity, contribute to the angiogenic process.

"Recently ADAMs have been linked to other biological processes, such as cell migration and adhesion, and activation of signalling pathways by shedding of membrane bound cytokines and growth factors"

\section{Membrane anchored SPs}

Recently, rapidly expanding subgroups of SPs have been recognised that are associated with the plasma membrane. These membrane anchored SPs are linked either through a C-terminal transmembrane domain (type I SP), via a GPI linkage (GPI anchored SP), or via an N-terminal transmembrane domain with a cytoplasmic extension (type II transmembrane SP or TTSP) (fig 2). ${ }^{67}$ The GPI anchored SPs and type I SPs both contain a hydrophobic domain at their C-terminus and are very similar in length, ranging from 310 to 370 amino acid residues. The GPI anchored proteases may be involved in the dynamic microenvironment of lipid rafts, participating in transduction complexes. The TTSPs share several structural features: an $\mathrm{N}$-terminal cytoplasmic domain of 20 to 160 amino acids, a type II transmembrane sequence, a central region of variable length with modular structural domains, and a C-terminal catalytic region with all the features of SPs. ${ }^{57}{ }^{69}$ To date, at least 15 TTSPs have been described and are listed in fig $2 .^{67-72}$

Membrane anchored SPs are interesting because of their potential capacity to participate in the matrix remodelling associated with cancer. ${ }^{69}$ Their cytoplasmic tail suggests that at least some of them function in intracellular signal transduction. In addition, crosstalk between different proteolytic systems is emphasised by the ability of MT-SPI to activate uPA. ${ }^{73}$ Although their functions are still unclear, they probably contribute to cancer progression because they are overexpressed in several types of cancer. ${ }^{67}{ }^{68}$ 75-81 Matriptase/MT-SPl has been implicated in tumour growth and metastasis in murine models of prostate cancer. ${ }^{82} 83$ Prometastatic effects have been associated with the stabilisation of active matriptase-1 by glycosylation. ${ }^{84}$ Recently, several TTSPs have been reported to be expressed during microvascular endothelial cell morphogenesis, ${ }^{85}$ suggesting that they have a function in angiogenesis. Membrane anchored SPs probably have complex functions because the upregulation and downregulation of their expression has been associated with cancer progression. ${ }^{67}$ Further studies are required to elucidate the individual functions of each membrane anchored SP.

\section{ROLE OF THE DIFFERENT PROTEOLYTIC SYSTEMS IN TUMORAL ANGIOGENESIS}

A link between the plasminogen system, MMPs, and cancer has been established through extensive studies of tumour biology in both human tissues and animal models. ${ }^{10} 1286-88$ Although it is anticipated that ADAMs and TTSPs play a role in tumour progression and angiogenesis this has yet to be demonstrated. Mice deficient in one of the plasminogen system components or one MMP or inhibitor have been generated, ${ }^{59-93}$ and have in some cases revealed unanticipated roles for previously characterised proteinases or their inhibitors. ${ }^{599-94}$

\section{Role of the plasminogen-plasmin system in tumoral angiogenesis and paradoxical functions of PAI-1}

A contribution of the plasminogen-plasmin system to tumour progression is suggested by the following: (a) increased expression of UPA, UPAR, and PAI-1 in various tumours, (b) the use of antisense mRNA, and (c) the administration of natural or synthetic serine proteinase inhibitors, UPA antagonists, or antibodies. ${ }^{29}$ This is further supported by the delayed angiogenesis seen recently in plasminogen deficient mice in an in vitro model of aortic rings embedded in a collagen gel, ${ }^{95}$ in addition to an in vivo model of malignant keratinocyte transplantation. ${ }^{96}$ Accordingly, loss of either plasminogen activator or plasminogen was shown to reduce T24l fibrosarcoma ${ }^{9798}$ and carcinoma ${ }^{99}$ tumour growth. In contrast, no difference in tumour growth was seen in a comparative study of control and plasminogen deficient mice using the PymT mouse mammary tumour model. ${ }^{100}{ }^{101}$ Although angiogenic endothelial cells require UPA and plasmin to degrade extracellular matrix components and to migrate, plasmin proteolysis needs to be controlled by a physiological inhibitor, such as PAI-1, to allow the stabilisation of the surrounding matrix and the assembly of endothelial cells into channels. ${ }^{2}{ }^{102}$ The importance of balanced proteolysis in the process of angiogenesis might provide an explanation for the dual role of proteinases and inhibitors in angiogenesis. Indeed, surprisingly, PAI-1 is a strong negative prognostic marker in different types of cancer. ${ }^{12}{ }^{103}$ This could be explained by a simultaneous enhancement in UPA and PAI-l expression, resulting in a net excess of proteolytic activity. Alternatively, this paradoxical clinical observation may be related to a potential direct role of PAI-1 in cancer cell migration and invasion. Studies in PAI-1 deficient mice have revealed that PAI- 1 is essential for the vascularisation of skin tumours. ${ }^{9496}$ The requirement for host PAI-l during tumour angiogenesis has been confirmed in a fibrosarcoma mode ${ }^{97}$ and in the mouse aortic ring model. ${ }^{95}$ However, it is likely that PAI- 1 is not of general importance in tumour progression and its angiogenic effect might be dependent on the tumour type, its cellular source (tumour cells versus host cells) (personal unpublished data, 2003), its concentration, and the step of cancer progression that is being considered. Indeed, PAI-1 deficiency did not affect sarcoma development, melanoma cell metastasis, ${ }^{104}$ or primary tumour growth and dissemination in a genetic model of mammary adenocarcinoma. ${ }^{105}$ Recently, a dose dependent effect of PAI-1 has been demonstrated in the aortic ring assay, ${ }^{95}$ in bFGF induced angiogenesis, ${ }^{106}$ and in choroidal angiogenesis. ${ }^{107}$ Therefore, 
PAI-1 appears to be proangiogenic at physiological concentrations and antiangiogenic at high, pharmacological concentrations.

\begin{abstract}
"Surprisingly, plasminogen activator inhibitor 1 is a strong negative prognostic marker in different types of cancer"
\end{abstract}

In addition to its ability to control pericellular proteolysis, PAI- 1 could act through its capacity to interact with UPAR, integrins, and vitronectin, thereby controlling cell migration. ${ }^{12}{ }^{108-110}$ Therefore, PAI-1 can competitively inhibit the uPAR dependent attachment of cells to vitronectin. Recently, PAI- 1 has been shown to detach cells by disrupting uPARvitronectin and integrin-vitronectin interactions. ${ }^{111}$ To investigate the mechanism of action of PAI-1, adenoviruses were used to deliver two mutant forms of PAI- 1 to PAI- 1 deficient mice in the transplantation system of malignant keratinocytes $^{96}$ and in the aortic ring assay. ${ }^{95}$ In both models, angiogenesis is restored only by the PAI-l mutant that retains plasminogen activator inhibitory activity, but not by the mutant that can interact with vitronectin but has impaired proteolytic control. These findings demonstrate that, in these models, PAI- 1 requirement is merely related to its capacity to inhibit excessive proteolysis, rather than to interact with vitronectin. In a separate study using PAI- I mutants, the inhibition of bFGF induced angiogenesis in the CAM assay requires both the antiprotease activity of PAI- 1 and its vitronectin binding capacity. ${ }^{106}$ Therefore, the mechanism of PAI-1 action will probably be dependent on the experimental setting, the in vivo situation, and the type of cancer.

\section{Role of MT1-MMP during tumoral angiogenesis and paradoxical functions of TIMPs}

The recent generation of MTl-MMP deficient mice revealed its involvement in skeletal development. ${ }^{9112}$ The role of MT1MMP during tumour angiogenesis has only been recently established. The overexpression of MTl-MMP in human melanoma, ${ }^{113}$ breast adenocarcinoma, ${ }^{114}$ and glioma cells ${ }^{115}{ }^{116}$ is associated with enhanced in vitro invasion and increased in vivo tumour growth and vascularisation. MTl-MMP might contribute to tumour angiogenesis through different mechanisms including at least: (a) the activation of $\alpha v \beta 3$ integrin, which plays a major role during angiogenesis ${ }^{117}$; (b) fibrinolytic activity ${ }^{44}{ }^{45}$; (c) collagenolytic activity ${ }^{118}$; (d) pericellular proteolysis, directly or indirectly, by activating pro-MMP2 and pro-MMP-13 and thereby promoting cell invasion and migration; and (e) the transcriptional regulation of VEGF expression. ${ }^{114} 116$

Consistent with the prevailing notion that angiogenesis requires at least MT-MMP mediated proteolysis, TIMPs have been shown to suppress not only tumour invasion and metastasis, but also tumour growth and neovascularisation in several tumour models. ${ }^{29}{ }^{119-123}$ Paradoxically, the association between poor prognosis and high levels of expression of TIMPs has been reported for several cancer types. ${ }^{124}{ }^{125}$ An increasing body of evidence suggests that TIMPs are multifunctional proteins that can have both an inhibitory or stimulatory effect on tumorigenesis. ${ }^{29}$ TIMPs promote the proliferation of some cell types, and their antiapoptotic effects may favour tumour expansion during the onset and early growth of the primary tumour. ${ }^{29}{ }^{126-128}$ The antiangiogenic activity of TIMP-2 could be linked to the direct control of MMP proteolysis, an inhibitory effect on endothelial cell proliferation, ${ }^{129}$ and/or the downregulation of VEGF. ${ }^{130}$ In contrast, TIMP-2 also plays a role in the activation of proMMP-2 as an adaptor molecule. ${ }^{3654}$ A ternary complex composed of MT1-MMP-TIMP-2-pro-MMP-2 is thought to
Take home messages

- Serine proteases (plasminogen-plasmin system) and matrix metalloproteases (MMPs) are overexpressed in many human cancers

- The activity of serine proteases is controlled by physiological inhibitors, namely: plasminogen activator inhibitors (PAI-1 and PAI-2) and tissue inhibitors of metalloproteases (TIMPs)

- Their contribution to cancer invasion and metastasis formation was initially related to their capacity to degrade extracellular matrix components, although they now appear to be multifunctional molecules, whose list of substrates has recently been extended to at least cell surface molecules, growth factors, growth factor binding proteins, and cytokines/chemokines

- New membrane associated proteases have been identified: a disintegrin and metalloproteases, membrane-type MMPs, and type II serine proteases. Together with the plasminogen-plasmin system they control cell surface proteolysis, which has emerged as an important mechanism to regulate cell growth, migration, invasion, metastasis, and angiogenesis

- Dual functions of their physiological inhibitors have been identified, explaining why high rather than low concentrations of PAI-1 and TIMPs predict poor survival in human cancer

cluster pro-MMP-2 at the cell surface near a TIMP-2 free MT1-MMP molecule, initiating the processing of the bound pro-MMP-2 (fig 4). This process could be facilitated by MTIMMP oligomerisation. ${ }^{131} 132$ According to this model, the activation of pro-MMP-2 at the cell surface is regulated by the balance between the MTl-MMP-TIMP-2 complex (MMP-2 receptor) and TIMP-2 free MT1-MMP (pro-MMP-2 activator). Therefore, like PAI-1, the effect of TIMP-2 on angiogenesis could be dose dependent. In addition, the expression of MT1-MMP by tumour cells has been shown to mediate the internalisation and intracellular degradation of TIMP-2, thereby altering the balance between active MMPs and TIMPs..$^{53}$

\section{CONCLUDING REMARKS}

The establishment of a causal relation between protease expression and tumour progression has prompted the development of MMP inhibitors, UPA or UPAR antagonists, inhibitors of PAI-1, and MMP inhibitors combined with the $\mathrm{N}$-terminal fragment of uPA. ${ }^{10} 122787133134$ Because studies have indicated a functional overlap between SPs and MMPs in wound healing, ${ }^{135}{ }^{136}$ a similar functional overlap is expected in cancer invasion. Therefore, arresting different steps of cancer progression will require the combined use of inhibitors of both classes. Undoubtedly, future studies of recently discovered or new membrane associated proteases will be crucial to the better understanding of the role of pericellular proteolysis in cancer and for the development of new anticancer strategies.

\section{ACKNOWLEDGEMENTS}

This work was supported by grants from the Communauté Française de Belgique (Actions de Recherches Concertées), the Commission of European Communities (FP5, FP6), the Fonds National de la Recherche Scientifique (FNRS, Belgium), the Fédération Belge Contre le Cancer, the FB Assurances, the DGTRE from the "Région 
Wallonne", and the Interuniversity Attraction Poles programmeBelgian Science Policy (Brussels, Belgium).

\section{Authors' affiliations \\ A Noel, C Maillard, N Rocks, M Jost, V Chabottaux, N E Sounni, \\ E Maquoi, D Cataldo, J M Foidart, Laboratory of Tumour and Development Biology, University of Liège, Sart Tilman, B-4000 Liège, Belgium}

\section{REFERENCES}

Carmeliet P, Jain RK. Angiogenesis in cancer and other diseases. Nature 2000;407:249-57

2 Pepper MS. Role of the matrix metalloproteinase and plasminogen activatorplasmin systems in angiogenesis. Arterioscler Thromb Vasc Biol 2001;21:1104-17.

3 Puente XS, Sanchez LM, Overall CM, et al. Human and mouse proteases: a comparative genomic approach. Nat Rev Genet 2003;4:544-58.

4 Rifkin DB, Mazzieri R, Munger JS, et al. Proteolytic control of growth factor availability. APMIS 1999;107:80-5.

5 Egeblad M, Werb Z. New functions for the matrix metalloproteinases in cancer progression. Nat Rev Cancer 2002;2:161-74.

6 McQuibban GA, Gong JH, Wong JP, et al. Matrix metalloproteinase processing of monocyte chemoattractant proteins generates CC chemokine receptor antagonists with anti-inflammatory properties in vivo. Blood 2002; 100: 1160-7.

7 Luttun A, Carmeliet P. Genetic studies on the role of proteinases and growth factors in atherosclerosis and aneurysm formation. Ann NY Acad Sci 2001;947:124-32

8 Collen D. The plasminogen (fibrinolytic) system. Thromb Haemost 1999:82:259-70.

9 Parfyonova YV, Plekhanova OS, Tkachuk VA. Plasminogen activators in vascular remodeling and angiogenesis. Biochemistry Mosc 2002;67:119-34.

10 Andreasen PA, Egelund R, Petersen $\mathrm{HH}$. The plasminogen activation system in tumor growth, invasion, and metastasis. Cell Mol Life Sci 2000:57:25-40.

11 Wind T, Hansen M, Jensen JK, et al. The molecular basis for anti-proteolytic and non-proteolytic functions of plasminogen activator inhibitor type-1: roles of the reactive centre loop, the shutter region, the flexible joint region and the small serpin fragment. Biol Chem 2002:383:21-36.

12 Rakic JM, Maillard C, Jost $M$, et al. Role of plasminogen activator-plasmin system in tumor angiogenesis. Cell Mol Life Sci 2003;60:463-73.

13 Carmeliet $\mathbf{P}$, Collen D. Transgenic mouse models in angiogenesis and cardiovascular disease. J Pathol 2000;190:387-405.

14 Blasi F. UPA, uPAR, PAI-1: key intersection of proteolytic, adhesive and chemotactic highways? Immunol Today 1997;18:415-17

15 Bugge TH, Kombrinck KW, Flick MJ, et al. Loss of fibrinogen rescues mice from the pleiotropic effects of plasminogen deficiency. Cell 1996:87:709-19.

16 Chapman HA. Plasminogen activators, integrins, and the coordinated regulation of cell adhesion and migration. Curr Opin Cell Biol 1997;9:714-24.

17 Preissner KT, Kanse SM, May AE. Urokinase receptor: a molecular organizer in cellular communication. Curr Opin Cell Biol 2000;12:621-8.

18 Kjoller $\mathrm{L}$. The urokinase plasminogen activator receptor in the regulation of the actin cytoskeleton and cell motility. Biol Chem 2002;383:5-19.

19 Blasi F, Carmeliet P. uPAR: a versatile signalling orchestrator. Nat Rev Mol Cell Biol 2002;3:932-43.

20 Blasi $F$. The urokinase receptor. A cell surface, regulated chemokine. APMIS 1999;107:96-101

21 Blasi F. Proteolysis, cell adhesion, chemotaxis, and invasiveness are regulated by the u-PA-u-PAR-PAI-1 system. Thromb Haemost 1999;82:298-304.

22 Busso N, Masur SK, Lazega D, et al. Induction of cell migration by prourokinase binding to its receptor: possible mechanism for signal transduction in human epithelial cells. J Cell Biol 1994;126:259-70.

23 Xue W, Mizukami I, Tod III RF, et al. Urokinase-type plasminogen activator receptors associate with $\beta 1$ and $\beta 3$ integrins of fibrosarcoma cells: dependence on extracellular matrix components. Cancer Res 1997; 57:1682-9

24 Wei $Y$, Yang X, Liu $Q$, et al. A role for caveolin and the urokinase receptor in integrin-mediated adhesion and signaling. J Cell Biol 1999;144:1285-94.

25 Sternlicht MD, Werb Z. How matrix metalloproteinases regulate cell behavior. Annu Rev Cell Dev Biol 2001;17:463-516.

26 Brinckerhoff CE, Matrisian LM. Matrix metalloproteinases: a tail of a frog that became a prince. Nat Rev Mol Cell Biol 2002;3:207-14.

27 Overall CM, Lopez-Otin C. Strategies for MMP inhibition in cancer: innovations for the post-trial era. Nat Rev Cancer 2002;2:657-72.

28 Zucker S, Pei D, Cao J, et al. Membrane type-matrix metalloproteinases (MT-MMP). Curr Top Dev Biol 2003;54:1-74.

29 Jiang Y, Goldberg ID, Shi YE. Complex roles of tissue inhibitors of metalloproteinases in cancer. Oncogene 2002;21:2245-52.

30 Oh J, Takahashi R, Kondo S, et al. The membrane-anchored MMP inhibitor RECK is a key regulator of extracellular matrix integrity and angiogenesis. Cell 2001; 107:789-800.

31 Weaver VM. Membrane-associated MMP regulators: novel cell adhesion tumor suppressor proteins? Dev Cell 2002;2:6-7.
32 Takino $\mathrm{T}$, Sato $\mathrm{H}$, Yamamoto $\mathrm{E}$, et al. Cloning of a human gene potentially encoding a novel matrix metalloproteinase having a C-terminal transmembrane domain. Gene 1995;155:293-8.

33 Will $H$, Hinzmann B. cDNA sequence and mRNA tissue distribution of a novel human matrix metalloproteinase with a potential transmembrane segment. Eur J Biochem 1995;231:602-8.

34 Llano E, Pendas AM, Freije JP, et al. Identification and characterization of human MT5-MMP, a new membrane-bound activator of progelatinase is overexpressed in brain tumors. Cancer Res 1999:59:2570-6.

35 Yana I, Seiki M. MT-MMPs play pivotal roles in cancer dissemination. Clin Exp Metastasis 2002;19:209-15.

36 Strongin AY, Collier I, Bannikov G, et al. Mechanism of cell surface activation of 72-kDa type IV collagenase. Isolation of the activated form of the membrane metalloprotease. J Biol Chem 1995;270:5331-8.

37 Zucker S, Drews M, Conner C, et al. Tissue inhibitor of metalloproteinase-2 (TIMP-2) binds to the catalytic domain of the cell surface receptor, membrane type 1-matrix metalloproteinase 1 (MT1-MMP). J Biol Chem 1998;273:1216-22.

38 Overall CM, King AE, Bigg HF, et al. Identification of the TIMP-2 binding site on the gelatinase $\mathrm{A}$ hemopexin $\mathrm{C}$-domain by site-directed mutagenesis and the yeast two-hybrid system. Ann N Y Acad Sci 1999;878:747-53.

39 Deryugina El, Ratnikov B, Monosov E, et al. MT1-MMP initiates activation of pro-MMP-2 and integrin alphavbeta3 promotes maturation of MMP-2 in breast carcinoma cells. Exp Cell Res 2001;263:209-23.

40 Morrison CJ, Butler GS, Bigg HF, et al. Cellular activation of MMP-2 (gelatinase A) by MT2-MMP occurs via a TIMP-2-independent pathway. J Biol Chem $2001 ; 276: 47402-10$.

41 Knauper V, Lopez-Otin C, Smith B, et al. Biochemical characterization of human collagenase-3. J Biol Chem 1996;271:1544-50.

42 d'Ortho MP, Will H, Atkinson S, et al. Membrane-type matrix metalloproteinases 1 and 2 exhibit broad-spectrum proteolytic capacities comparable to many matrix metalloproteinases. Eur J Biochem 1997;250:751-7

43 Koshikawa N, Giannelli G, Cirulli V, et al. Role of cell surface metalloprotease MT1-MMP in epithelial cell migration over laminin-5. J Cell Biol 2000;148:615-24.

44 Hotary K, Allen E, Punturieri A, et al. Regulation of cell invasion and morphogenesis in a three-dimensional type I collagen matrix by membranetype matrix metalloproteinases 1, 2, and 3. J Cell Biol 2000;149:1309-23.

45 Hotary KB, Yana I, Sabeh F, et al. Matrix metalloproteinases (MMPs) regulate fibrin-invasive activity via MT1-MMP-dependent and -independent processes. J Exp Med 2002; 195:295-308.

46 Giannelli G, Falk-Marzillier J, Schiraldi $O$, et al. Induction of cell migration by matrix metalloprotease- 2 cleavage of laminin-5. Science 1997;277:225-8.

47 Gilles C, Polette M, Coraux C, et al. Contribution of MT1-MMP and of human laminin-5 gamma2 chain degradation to mammary epithelial cell migration. J Cell Sci 2001;114:2967-76.

48 Kajita $M$, Itoh $Y$, Chiba T, et al. Membrane-type 1 matrix metalloproteinase cleaves CD44 and promotes cell migration. J Cell Biol 2001;153:893-904

49 Belkin AM, Akimov SS, Zaritskaya LS, et al. Matrix-dependent proteolysis of surface transglutaminase by membrane-type metalloproteinase regulates cancer cell adhesion and locomotion. J Biol Chem 2001;276:18415-22.

50 Wang $X$, Pei D. Shedding of membrane type matrix metalloproteinase 5 by a furin-type convertase: a potential mechanism for down-regulation. J Biol Chem $2001 ; 276: 35953-60$.

51 Uekita T, Itoh Y, Yana I, et al. Cytoplasmic tail-dependent internalization of membrane-type 1 matrix metalloproteinase is important for its invasionpromoting activity. J Cell Biol 2001;155:1345-56

52 Maquoi E, Peyrollier K, Noel A, et al. Regulation of membrane-type 1 matrix metalloproteinase activity by vacuolar H+-ATPases. Biochem J 2003;373:19-24.

53 Maquoi E, Frankenne F, Baramova E, et al. Membrane type 1 matrix metalloproteinase-associated degradation of tissue inhibitor of metalloproteinase 2 in human tumor cell lines [in process citation]. J Biol Chem 2000;275: 11368-78.

54 Butler GS, Butler MJ, Atkinson SJ, et al. The TIMP2 membrane type 1 metalloproteinase "receptor" regulates the concentration and efficient activation of progelatinase A. A kinetic study. J Biol Chem 1998:273:871-80

55 Killar L, White J, Black R, et al. Adamalysins. A family of metzincin including TNF-alpha converting enzyme (TACE). Ann N Y Acad Sci 1999;878:442-52.

56 Blobel CP. Functional and biochemical characterization of ADAMs and their predicted role in protein ectodomain shedding. Inflamm Res 2002;51:83-4.

57 Bogenrieder T, Herlyn M. Cell-surface proteolysis, growth factor activation and intercellular communication in the progression of melanoma. Crit Rev Oncol Hematol 2002;44:1-15.

58 Becherer JD, Blobel CP. Biochemical properties and functions of membraneanchored metalloprotease-disintegrin proteins (ADAMs). Curr Top Dev Biol 2003; $54: 101-23$

59 Black RA, White JM. ADAMs: focus on the protease domain. Curr Opin Cell Biol 1998; 10:654-659.

60 Kheradmand F, Werb Z. Shedding light on sheddases: role in growth and development. Bioessays 2002;24:8-12.

61 Black RA. Tumor necrosis factor-alpha converting enzyme. Int J Biochem Cell Biol 2002;34:1-5.

62 Iba K, Albrechtsen R, Gilpin BJ, et al. Cysteine-rich domain of human ADAM 12 (meltrin alpha) supports tumor cell adhesion. Am J Pathol $1999 ; 154: 1489-501$ 
63 McQuibban GA, Gong JH, Tam EM, et al. Inflammation dampened by gelatinase A cleavage of monocyte chemoattractant protein-3. Science 2000;289:1202-6

64 Yoshimura T, Tomita T, Dixon MF, et al. ADAMs (a disintegrin and metalloproteinase) messenger RNA expression in Helicobacter pyloriinfected, normal, and neoplastic gastric mucosa. J Infect Dis 2002; 185:332-40

65 Amour A, Knight CG, Webster A, et al. The in vitro activity of ADAM-10 is inhibited by TIMP-1 and TIMP-3. FEBS Lett 2000;473:275-9.

66 Zhang XP, Kamata T, Yokoyama K, et al. Specific interaction of the recombinant disintegrin-like domain of MDC-15 (metargidin, ADAM-15) with integrin alphavbeta3. J Biol Chem 1998;273:7345-50.

67 Netzel-Arnett S, Hooper JD, Szabo R, et al. Membrane anchored serine proteases: a rapidly expanding group of cell surface proteolytic enzymes with potential roles in cancer. Cancer Metastasis Rev 2003;22:237-58.

68 Szabo R, Wu Q, Dickson RB, et al. Type II transmembrane serine proteases. Thromb Haemost 2003;90:185-93.

69 Hooper JD, Clements JA, Quigley JP, et al. Type II transmembrane serine proteases. Insights into an emerging class of cell surface proteolytic enzymes. J Biol Chem 2001;276:857-60.

70 Kim DR, Sharmin S, Inove M, et al. Cloning and expression of novel mosaic serine proteases with and without a transmembrane domain from human lung. Biochim Biophys Acta 2001;1518:204-9.

71 Lang JC, Schuller DE. Differential expression of a novel serine protease homologue in squamous cell carcinoma of the head and neck. Br J Cance 2001;84:237-43.

72 Velasco G, Cal S, Quesada V, et al. Matriptase-2, a membrane-bound mosaic serine proteinase predominantly expressed in human liver and showing degrading activity against extracellular matrix proteins. J Biol Chem 2002;277:37637-46.

73 Lee SL, Dickson RB, Lin CY. Activation of hepatocyte growth factor and urokinase/plasminogen activator by matriptase, an epithelial membrane serine protease. J Biol Chem 2000;275:36720-5.

74 Takeuchi T, Harris JL, Huang W, et al. Cellular localization of membranetype serine protease 1 and identification of protease-activated receptor-2 and single-chain urokinase-type plasminogen activator as substrates. J Biol Chem 2003;275:26333-42.

75 Oberst M, Anders J, Xie B, et al. Matriptase and HAl-1 are expressed by normal and malignant epithelial cells in vitro and in vivo. Am J Pathol 2001;158:1301-11.

76 Dhanasekaran SM, Barrette TR, Ghosh D, et al. Delineation of prognostic biomarkers in prostate cancer. Nature $2001 ; 412: 822-6$.

77 Afar DE, Vivanco I, Hubert RS, et al. Catalytic cleavage of the androgenregulated TMPRSS2 protease results in its secretion by prostate and prostate cancer epithelia. Cancer Res 2001;61:1686-92.

78 Wallrapp C, Hahnel S, Muller-Pillasch F, et al. A novel transmembrane serine protease (TMPRSS3) overexpressed in pancreatic cancer. Cancer Res 2000:60:2602-6.

79 Benaud CM, Oberst M, Dickson RB, et al. Deregulated activation of matriptase in breast cancer cells. Clin Exp Metastasis 2002;19:639-49.

80 Bhatt AS, Takeuchi T, Ylstra B, et al. Quantitation of membrane type serine protease 1 (MT-SP1) in transformed and normal cells. Biol Chem 2003;384:257-66.

81 Kang JY, Dolled-Filhart M, Ocal IT, et al. Tissue microarray analysis of hepatocyte growth factor/Met pathway components reveals a role for Met matriptase, and hepatocyte growth factor activator inhibitor 1 in the progression of node-negative breast cancer. Cancer Res 2003;63:1101-5.

82 Lin CY, Anders J, Johnson M, et al. Purification and characterization of a complex containing matriptase and a Kunitz-type serine protease inhibitor from human milk. J Biol Chem 1999;274:18237-42.

83 Takeuchi T, Shuman MA, Craik CS. Reverse biochemistry: use of macromolecular protease inhibitors to dissect complex biological processes and identify a membrane-type serine protease in epithelial cancer and normal tissue. Proc Natl Acad Sci U S A 1999;96:11054-61.

84 Ihara $\mathrm{S}$, Miyoshi $\mathrm{E}, \mathrm{Ko} \mathrm{JH}$, et al. Prometastatic effect of $\mathrm{N}$ acetylglucosaminyltransferase $\mathrm{V}$ is due to modification and stabilization of active matriptase by adding beta 1-GlcNAc branching. J Biol Chem 2003;277:16960-7.

85 Aimes RT, Ziilstra A, Hooper JD, et al. Endothelial cell serine proteases expressed during vascular morphogenesis and angiogenesis. Thromb Haemost 2003;89:561-72.

86 Schmitt $M$, Wilhelm $O$, Reuning $U$, et al. The urokinase plasminogen activator system as a novel target for tumour therapy. Fibrinolysis and Proteolysis 2000;14:114-32.

87 Mazar AP. The urokinase plasminogen activator receptor (UPAR) as a target for the diagnosis and therapy of cancer. Anticancer Drugs $2001 ; 12: 387-400$

88 Vihinen P, Kahari VM. Matrix metalloproteinases in cancer: prognostic markers and therapeutic targets. Int J Cancer 2002;99:157-66.

89 Carmeliet P, Collen D. Development and disease in proteinase-deficient mice: role of the plasminogen, matrix metalloproteinase and coagulation system. Thromb Res 1998;91:255-85.

90 Masson R, Lefebvre O, Noel A, et al. In vivo evidence that the stromelysin-3 metalloproteinase contributes in a paracrine manner to epithelial cell malignancy. J Cell Biol 1998;140:1535-41.

91 Zhou Z, Apte SS, Soininen R, et al. Impaired endochondral ossification and angiogenesis in mice deficient in membrane-type matrix metalloproteinase I. Proc Natl Acad Sci U S A 2000;97:4052-57.

92 Carmeliet P, Collen D. Gene manipulation and transfer of the plasminogen and coagulation system in mice. Semin Thromb Hemost 1996;22:525-42.
93 Leco KJ, Waterhouse $\mathrm{P}$, Sanchez $\mathrm{OH}$, et al. Spontaneous air space enlargement in the lungs of mice lacking tissue inhibitor of metalloproteinases-3 (TIMP-3). J Clin Invest 2001;108:817-29.

94 Bajou K, Noel A, Gerard RD, et al. Absence of host plasminogen activator inhibitor 1 prevents cancer invasion and vascularization. Nat Med 1998;4:923-8.

95 Devy L, Blacher S, Grignet-Debrus C, et al. The pro- or antiangiogenic effect of plasminogen activator inhibitor 1 is dose dependent. FASEB $J$ 2002; 16:147-54.

96 Bajou K, Masson V, Gerard RD, et al. The plasminogen activator inhibitor PAl- 1 controls in vivo tumor vascularization by interaction with proteases, not vitronectin: implications for antiangiogenic strategies. J Cell Biol 2001;152:777-84.

97 Gutierrez LS, Schulman A, Brito-Robinson T, et al. Tumor development is retarded in mice lacking the gene for urokinase-type plasminogen activator or its inhibitor, plasminogen activator inhibitor-1. Cancer Res 2000;60:5839-47.

98 Curino A, Mitola DJ, Aaronson $\mathrm{H}$, et al. Plasminogen promotes sarcoma growth and suppresses the accumulation of tumor-infiltrating macrophages. Oncogene 2002;21:8830-42.

99 Bugge TH, Kombrinck KW, Xiao Q, et al. Growth and dissemination of Lewis lung carcinoma in plasminogen-deficient mice. Blood 1997:90:4522-31.

100 Bugge TH, Lund LR, Kombrinck KK, et al. Reduced metastasis of polyoma virus middle T antigen-induced mammary cancer in plasminogen-deficient mice. Oncogene 1998;16:3097-104.

101 Sabapathy KT, Pepper MS, Kiefer F, et al. Polyoma middle T-induced vascular tumor formation: the role of the plasminogen activator/plasmin system. J Cell Biol 1997; 137:953-63.

102 Montesano R, Pepper MS, Mohle-Steinlein U, et al. Increased proteolytic activity is responsible for the aberrant morphogenetic behavior of endothelial cells expressing the middle T oncogene. Cell 1990;62:435-45.

103 Noel A, Bajou K, Masson V, et al. Regulation of cancer invasion and vascularization by plasminogen activator inhibitor-1. Fibrinolysis and Proteolysis 1999; 13:220-5.

104 Eitzman DT, Krauss JC, Shen T, et al. Lack of plasminogen activator inhibitor1 effect in a transgenic mouse model of metastatic melanoma. Blood 1996;87:4718-22

105 Almholt K, Nielsen BS, Frandsen TL, et al. Metastasis of transgenic breast cancer in plasminogen activator inhibitor-1 gene-deficient mice. Oncogene 2003;22:4389-97.

106 Stefansson S, Petitclerc E, Wong MK, et al. Inhibition of angiogenesis in vivo by plasminogen activator inhibitor-1.J Biol Chem $2001 ; 276: 8135-41$.

107 Rakic JM, Lambert V, Munaut C, et al. Mice without uPA, IPA, or plasminogen genes are resistant to experimental choroidal neovascularization. Invest Ophthalmol Vis Sci 2003;44:1732-9.

108 Deng G, Curriden SA, Wang S, et al. Is plasminogen activator inhibitor- 1 the molecular switch that governs urokinase receptor-mediated cell adhesion and release? J Cell Biol 1996;134:1-9.

109 Waltz DA, Natkin LR, Fujita RM, et al. Plasmin and plasminogen activator inhibitor type 1 promote cellular motility by regulating the interaction between the urokinase receptor and vitronectin. J Clin Invest 1997; 100:58-67.

110 Kayagaki N, Kawasaki A, Ebata T, et al. Metalloproteinase-mediated release of human Fas ligand. J Exp Med 1995; 182:1777-83.

111 Czekay RP, Aertgeerts K, Curriden SA, et al. Plasminogen activator inhibitor-1 detaches cells from extracellular matrices by inactivating integrins. J Cell Biol 2003;160:781-91.

112 Holmbeck K, Bianco P, Caterina J, et al. MT1-MMP-deficient mice develop dwarfism, osteopenia, arthritis, and connective tissue disease due to inadequate collagen turnover. Cell 1999;99:81-92.

113 Sounni NE, Baramova EN, Munaut C, et al. Expression of membrane type matrix metalloproteinase (MT1-MMP) in A2058 melanoma cells is associated with MMP-2 activation and increased tumor growth and vascularization. Int J Cancer 2002;98:23-8.

114 Sounni NE, Devy L, Hajitou A, et al. MT1-MMP expression promotes tumor growth and angiogenesis through an up-regulation of vascular endothelial growth factor expression. FASEB J 2002;16:555-64.

115 Belien AT, Paganetti PA, Schwab ME. Membrane-type 1 matrix metalloprotease (MT1-MMP) enables invasive migration of glioma cells in central nervous system white matter. J Cell Biol 1999;144:373-84.

116 Deryugina EI, Soroceanu L, Strongin AY. Up-regulation of vascular endothelial growth factor by membrane-type 1 matrix metalloproteinase stimulates human glioma xenograft growth and angiogenesis. Cancer Res 2002:62:580-8.

117 Deryugina El, Bourdon MA, Jungwirth K, et al. Functional activation of integrin alpha $V$ beta 3 in tumor cells expressing membrane-type 1 matrix metalloproteinase. Int J Cancer 2000;86:15-23.

118 Hotary K, Allen E, Brooks PC, et al. Membrane type I matrix metalloproteinase usurps tumor growth control imposed by the threedimensional extracellular matrix. Cell 2003;1 14:33-45.

119 Kahari VM, Saarialho-Kere U. Matrix metalloproteinases and their inhibitors in tumour growth and invasion. Ann Med 1999;31:34-45.

120 Wang M, Liu YE, Greene J, et al. Inhibition of tumor growth and metastasis of human breast cancer cells transfected with tissue inhibitor of metalloproteinase 4. Oncogene 1997; 14:2767-74.

121 Ahonen M, Baker AH, Kahari VM. Adenovirus-mediated gene delivery of tissue inhibitor of metalloproteinases-3 inhibits invasion and induces apoptosis in melanoma cells. Cancer Res 1998;58:2310-15.

122 Noel A, Boulay A, Kebers F, et al. Demonstration in vivo that stromelysin-3 functions through its proteolytic activity. Oncogene 2000;19:1605-12. 
123 Noel A, Hajitou A, L'Hoir C et al. Inhibition of stromal matrix metalloproteases: effects on breast-tumor promotion by fibroblasts. Int J Cancer 1998;76:267-73.

124 Grignon DJ, Sakr W, Toth $M$, et al. High levels of tissue inhibitor of metalloproteinase-2 (TIMP-2) expression are associated with poor outcome in invasive bladder cancer. Cancer Res 1996;56:1654-9.

125 Remacle A, McCarthy K, Noel A, et al. High levels of TIMP-2 correlate with adverse prognosis in breast cancer. Int J Cancer 2000;89:118-21.

126 Baker $A H$, George SJ, Zaltsman $A B$, et al. Inhibition of invasion and induction of apoptotic cell death of cancer cell lines by overexpression of TIMP-3. Br J Cancer 1999;79:1347-55.

127 Guedez L, Courtemanch L, Stetler-Stevenson M. Tissue inhibitor of metalloproteinase (TIMP)-1 induces differentiation and an antiapoptotic phenotype in germinal center B cells. Blood 1998;92:1342-9.

128 Guedez L, McMarlin AJ, Kingma DW, et al. Tissue inhibitor of metalloproteinase-1 alters the tumorigenicity of Burkitt's lymphoma via divergent effects on tumor growth and angiogenesis. Am J Pathol 2001;158:1207-15.

129 Murphy AN, Unsworth EJ, Stetler-Stevenson WG. Tissue inhibitor of metalloproteinases-2 inhibits bFGF-induced human microvascular endothelial cell proliferation. J Cell Physiol 1993;157:351-8.
130 Hajitou A, Sounni NE, Devy L, et al. Down-regulation of vascular endothelia growth factor by tissue inhibitor of metalloproteinase-2: effect on in vivo mammary tumor growth and angiogenesis. Cancer Res 2001;61:3450-7.

131 Itoh $\mathrm{Y}$, Takamura A, Ito N, et al. Homophilic complex formation of MT1MMP facilitates proMMP-2 activation on the cell surface and promotes tumor cell invasion. EMBO J 2001;20:4782-93.

132 Lehti K, Lohi J, Juntunen MM, et al. Oligomerization through hemopexin and cytoplasmic domains regulates the activity and turnover of membrane-type matrix metalloproteinase. J Biol Chem 2002;277:8440-8.

133 Coussens LM, Fingleton B, Matrisian LM. Matrix metalloproteinase inhibitors and cancer: trials and tribulations. Science 2002;295:2387-92.

134 Lamfers ML, Grimbergen JM, Aalders MC, et al. Gene transfer of the urokinase-type plasminogen activator receptor-targeted matrix metalloproteinase inhibitor TIMP-1.ATF suppresses neointima formation more efficiently than tissue inhibitor of metalloproteinase-1. Circ Res 2002;91:945-52.

135 Dano K, Romer J, Nielsen BS, et al. Cancer invasion and tissue remodelingcooperation of protease systems and cell types. APMIS 1999;107:120-7.

136 Lund LR, Romer J, Bugge TH, et al. Functional overlap between two classes of matrix-degrading proteases in wound healing. EMBO J $1999 ; 18: 4645-56$ 